\title{
Information about Psychoactive Substances and Visually Impaired People: a Comparative Study between Brazil and Portugal
}

\author{
Fernanda Jorge Guimarães ${ }^{1}$, António Luís Rodrigues Faria de Carvalho², \\ Paulo César de Almeida ${ }^{3}$, Lorita Marlena Freitag Pagliuca4
}

\section{Abstract}

Objective: The study aimed to compare correct answers before and after access to information material on psychoactive substances for visually impaired people in Brazil and Portugal.

Method: Study with a quantitative approach, before-and-after type, held in institutions that provide care to people with visual impairment in Brazilian cities and in Porto, Portugal. Data were collected through information tests and analyzed by using the statistical software SPSS version 19.

Results: 62 people with visually impaired participated, equally distributed between the two countries, of which, in Brazil, all are blind and in Portugal $67.7 \%$ are blind and $32.3 \%$ have low vision. The average age in Brazil was 34.94 years old and in Portugal, 51.48 years old. The average of years of schooling was 14.81 in Brazil and 9.58 years in Portugal. In Brazil, 54.8\% said they had information about psychoactive substances, in Portugal, 90.3\%. In Brazil, there was a higher proportion of correct answers on questions that address addiction issues, problems related to drug use, specific effects of cocaine. In Portugal, there was a higher proportion of correct answers on issues related to factors that contribute to the use of substances, the effects of alcohol and tobacco and addiction.

Conclusion: The information about psychoactive substances is similar in the two study places in regarding the proportion of corrects answers. The theme that acquired most hit was associated with substance abuse.
1 Nursing Professor of the Centro Acadêmico de Vitória of the Federal University of Pernambuco. Vitória de Santo Antão, Pernambuco, Brazil.

2 Professor at Escola Superior de Enfermagem do Porto. Porto, Portugal.

3 Professor at the State University of Ceará. Fortaleza, Ceará, Brazil.

4 Professor, Department of Nursing, Federal University of Ceará. Researcher CNPq. Fortaleza, Ceará, Brazil.

Contact information:

Fernanda Jorge Guimarães.

Address: Universidade Federal de Pernambuco.

Tel: 558131144101.

झ ferjorgui@hotmail.com

Keywords

Information; Disorders Related to use of Substances; Visually Impaired. 


\section{Introduction}

The substance abuse has been a matter of public health as it relates to problems in the social, family, legal, health aspects of the individual. For example, the harmful use of alcohol causes disease and brings social and economic burden for societies [1].

In Brazil, alcohol is the first in the ranking of substances whose users become addicted. The illicit substances used one time in life were marijuana, and cocaine, with $6,8 \%$ and $3,8 \%$ respectively [2]. In Portugal, the illicit substance most commonly used is cannabis (9.4\%), whose sale is prohibited [3]. Study found that $8 \%$ of Portuguese students presented harmful consumption for alcohol. Of these, 7.5\% were addicted [4].

In Brazil, there has been investment in the professional training, establishment of medical offices in the street and in transitional shelters, but the users' needs have not been met by the service network.

It is emphasized that the care in this area should not be restricted to hospital admissions, but should be based on health promotion and prevention and seek early intervention to limit the complications of abuse in all population groups, including people with disabilities who need prevention programs that meet their particularities.

In order to reduce substance abuse, one of the important factors is the information on the main substances used and its consequences. Quality information enables individuals to decide more clearly about their health-related behaviors.

Information on psychoactive substances and hazards is one of the important protective factors to their abuse. On the other hand, among users of psychoactive substances, there is a lack of information or incomplete information [5].

There is the need for strategies that prevent substance abuse with the visually impaired, because usually the available materials are not accessible to this clientele.

A study found that people with visual impairments do not have enough information about the characteristics of psychoactive substances, their effects and consequences of abuse [6].

It was noted that there are few studies on substance abuse among people with disabilities and specifically studies that address health information to people with visual impairment to prevent substance abuse.

Thus, this study aimed to compare correct answers before and after access to information material on psychoactive substances for visually impaired people in Brazil and Portugal.

\section{Method}

This is a descriptive study, of "before-and-after" type, with quantitative approach, performed in associations for blind people in Northeastern Brazil, from State of Paraíba, Pernambuco, Piauí, Rio Grande do Norte and the State of Ceará and in the Association of Blinds and the Rehabilitation Center for people with disabilities in the city of Porto, Portugal. In Brazil, each institution has approximately 120 attendees, while in Porto this number reaches 500 members.

Study participants were visually impaired people in Brazil and Portugal. Visual impairment is classified in the categories blindness and low vision. Blindness is understood as visual capacity equal to or less than 0.05 in the better eye with the best optical correction, while low vision means visual capacity between 0.3 and 0.05 in the better eye with the best optical correction [7].

Inclusion criteria were being visually impaired, aged 18 years or older, of both genders. Individuals with multiple disabilities or who had difficulty in understanding the questions were excluded from the study. The evaluation of this last criterion was made by researcher through observation. It was used sampling by convenience. Data were collected by means of information tests, pre-test and post-test, developed for the study, as described below. 
Initially, authors elaborated a question bank with 50 statements from the text "Drugs: reflection for prevention". The text was written from scientific articles and materials of the Brazilian Ministry of Health and covers the following aspects: definition of psychoactive substances; main types of substances; physical, psychological and social effects produced by substances and strategies to prevent substance abuse [8].

In a second step, the question bank was presented to a group of five experts who analyzed the statements, as for the content, clarity of statements, ambiguity of answers, repetition or similarity. At this stage, four statements were excluded for not presenting adherence to the content of the text, one affirmative was removed since its statement had a technical content and three statements were modified for being too long, which resulted in 48 statements.

Finally, the experts classified the statements in true or false and also set the level of complexity of knowledge required to answer the question, namely: low, medium and high complexity. At this stage, six statements showed different responses among experts and were excluded from the question bank, which was comprised of 42 statements, distributed by level of complexity. Thus, 21 statements are of low complexity, 11 of medium and 10 of high complexity. To abide by the experts' suggestions, authors used the consensus criterion.

For this study, the statements contained in the question bank were chosen randomly to constitute the information assessment tests, namely, pre-test and post-test. Ten different statements were drawn for each test, of which three had low complexity, four, medium and three, high complexity. Thus, the pre-test and the post-test had similar degree of complexity.

The low complexity statements addressed issues related to harm from use of psychoactive substances, their types and the reasons for using them. In turn, the medium complexity statements approa- ched the discussion of the theme with students in the school environment and the occasional use of substances. Finally, the high complexity statements addressed on dependence, withdrawal of substances and specific effects of cocaine use.

Subsequently, study participants responded to the pre-test, classifying statements as true or false. Then, they used the text "Drugs: reflection for prevention", available as assistive technology in a computer with voice device to read the text. The educational text is seen as an assistive technology, because it is a resource, a methodology and a strategy to inform people with visual impairment on psychoactive substances. In turn, the voice synthesis program is a tool that helps the visually impaired person to access the text [8-9].

After reading the assistive technology, participants answered the post-test, classifying the statement as true or false.

The data were entered into an Excel spreadsheet and analyzed using statistical software SPSS version 19. Authors used measurement of central tendency such as mean and standard deviation for the variables: gender, age, education. The Wilcoxon test was used to verify the significance between the proportions of the answers in the pre and post-test in the investigated countries. It was adopted a confidence level of $95 \%$.

In Brazil, the study was approved by the Research Ethics Committee of the Federal University of Pernambuco (CAAE 08796212.2.0000.5208). In Porto, the study was submitted to the technical team and the direction of the association of blinds and rehabilitation center, which assessed the relevance and ethical aspects of the research and whose opinion was favorable to performing it.

\section{Results}

The study included 62 people with visual impairment, equally distributed between the two countries. In Brazil, all participants were blind and in Por- 
tugal $67.7 \%$ were blind and $32.3 \%$ of participants had low vision.

The average age in Brazil was 34.94 years old, while in Portugal it was 51.48 years old. In Brazil, there was greater participation of men (54.8\%) and in Portugal, of women (51.6\%). The average of years of education was 14.81 and 9.58 in Brazil and in Portugal, respectively.

In Brazil, $54.8 \%$ of participants reported having information on psychoactive substances, while in Portugal this result was $90.3 \%$.

Regarding the proportion of correct answers in the pre-test and in the post-test, the results were presented in sets of questions, according to the level of complexity, and also in individual questions, as shown in Table 1.

In Brazil, there was a higher proportion of correct answers in the question 4 of the pre-test and in questions 7 and 9 of the post-test. In Portugal, the questions with the highest proportion of correct answers were 2, 3 and 8 of the post-test. All participants answered correctly the question 10 of the pre-test and 8 of the post-test.

The results of the low and high complexity questions in the pre-test and post-test in Brazil showed significant differences. The averages of answers of the groups of questions in the two scenarios of the research are presented in Table 2 .

Table 1. Distribution of correct answers in pre and post-test in Brazil and Portugal, 2014.

\begin{tabular}{|c|c|c|c|c|c|c|c|c|c|c|}
\hline \multirow{3}{*}{ Statements } & \multicolumn{5}{|c|}{ Brazil } & \multicolumn{5}{|c|}{ Portugal } \\
\hline & \multicolumn{2}{|c|}{ Pre-test } & \multicolumn{2}{|c|}{ Post-test } & \multirow{2}{*}{ P-value ${ }^{1}$} & \multicolumn{2}{|c|}{ Pre-test } & \multicolumn{2}{|c|}{ Post-test } & \multirow{2}{*}{ P-value } \\
\hline & $\mathrm{N}$ & $\%$ & N & $\%$ & & N & $\%$ & $\mathrm{~N}$ & $\%$ & \\
\hline \multicolumn{11}{|c|}{ Low complexity } \\
\hline 1 & 28 & 90.3 & 15 & 51,6 & 0,066 & 28 & 90,3 & 09 & 70,9 & 0,002 \\
\hline 2 & 29 & 93.5 & 28 & 90,3 & 0,999 & 21 & 67,7 & 30 & 3,2 & 0,262 \\
\hline 3 & 24 & 77.4 & 27 & 87,1 & 0,779 & 20 & 64,5 & 30 & 96,8 & 0,202 \\
\hline P-value 1 & \multicolumn{5}{|c|}{$<0.0001$} & \multicolumn{5}{|c|}{0.025} \\
\hline \multicolumn{11}{|c|}{ Medium complexity } \\
\hline 4 & 30 & 96.8 & 30 & 96,8 & 1,000 & 31 & 100,0 & 29 & 93,5 & 0,897 \\
\hline 5 & 27 & 87.1 & 29 & 93,5 & 0,893 & 24 & 77,4 & 22 & 71,0 & 0,883 \\
\hline 6 & 18 & 58.1 & 28 & 90,3 & 0,183 & 15 & 48,4 & 13 & 41,9 & 0,851 \\
\hline 7 & 31 & 100.0 & 30 & 96,8 & 0,999 & 27 & 87,1 & 31 & 100,0 & 0,694 \\
\hline P-value 1 & \multicolumn{5}{|c|}{0.012} & \multicolumn{5}{|c|}{0.840} \\
\hline \multicolumn{11}{|c|}{ High complexity } \\
\hline 8 & 27 & 87.1 & 31 & 100,0 & 0,694 & 22 & 71,0 & 31 & 100,0 & 0,272 \\
\hline 9 & 29 & 93.5 & 30 & 96,8 & 0,999 & 28 & 90,3 & 29 & 93,5 & 0,999 \\
\hline 10 & 31 & 100.0 & 27 & 87,1 & 0,694 & 31 & 100,0 & 18 & 58,1 & 0,085 \\
\hline P-value 1 & \multicolumn{5}{|c|}{$<0.0001$} & \multicolumn{5}{|c|}{0.366} \\
\hline
\end{tabular}

Table 2. Distribution of averages of correct answers of low, medium and high complexity questions in Brazil and Portugal, 2014.

\begin{tabular}{|l|c|c|c|c|c|c|}
\multirow{2}{*}{ Country } & \multicolumn{3}{|c|}{ Pre-test } & \multicolumn{3}{c|}{ Post-test } \\
\cline { 2 - 7 } & \multicolumn{2}{|c|}{ Level of complexity } & \multicolumn{2}{c|}{ Level of complexity } \\
\cline { 2 - 7 } & Low & Medium & High & Low & Medium & High \\
\hline $\mathrm{Br}$ & 0.8710 & 0.8548 & 0.9355 & 0.4946 & 0.9435 & 0.9462 \\
$\mathrm{Pt}$ & 0.7419 & 0.7823 & 0.8710 & 0.5699 & 0.7661 & 0.8387 \\
\hline
\end{tabular}


The averages of correct answers to low complexity questions in the pre-test exceeded those of the post-test in both research sites. It was found that the averages of answers in the three levels of complexities in both locations are similar.

\section{Discussion}

Regarding the characteristics of the study participants, in Brazil, the majority was young, male and with more years of schooling; while in Portugal, the majority of respondents was adult and female. Contradictorily, in Brazil, people with disabilities belong, in most cases, to the age group above 65 years of age [10].

Education is a variable that can influence answer to questions. It is estimated that the more years of education the individual has, the greater the ability to answer correctly. It is important that the Assistive Technology is understandable to the user. A study pointed out that the nurse, when providing information, should be aware of the user's knowledge level [11]. In Brazil, there was a reduction in the illiteracy rate among people with disabilities, but $61.1 \%$ of this population still have no education or have not completed elementary school [10].

It is noteworthy that the majority of Portuguese participants stated having information about psychoactive substances; however, the averages of correct answers between the two countries were similar.

The average of correct answers in the mediumcomplexity questions was higher in the post-test than in the pre-test in the Brazilian reality. In both research sites, the average of correct answers was higher in the high-complexity questions when compared the low and medium complexity questions. This is noteworthy because the highly complex questions require from the participant more information on the subject evaluated, greater attention and interpretation to answer them. The individual must have information about the topic discussed and the ability to use it to answer questions [12]

Another aspect that may influence the answer to the questions is the way they are written. For the development of tests with true and false statements, it is recommended to avoid negative statements [12]. In this study, participants did not report difficulties in answering questions.

This corroborates with a study that showed that higher levels of education were associated with higher levels of literacy. The authors found that low literacy can be an obstacle to understanding health information [13]. Another study in Portugal found that people with high levels of education tend to have better health literacy levels [14].

Moreover, it was found that the themes addressed in the questions are more often reported in prevention programs and in the media, which may have favored the greater number of correct answers in high-complexity questions.

This study results differ from another, which identified that the rate of correct answers among students about AIDS and drugs was higher in low-complexity questions and it decreased as the degree of complexity of the questions increased, which shows that they had knowledge of themes, but there were gaps in information. The study also pointed out that the main source of information used by students is television [15].

School and television were cited as the main sources of information about psychoactive substances by people with visual impairment [6]. They identified other sources of information such as the family and the observation of negative experiences of friends who used substances abusively. The information was identified as a protective factor against substance abuse [5].

The television, also, can be used to prevention, as presented in study, realized in Netherlands, which evaluated the television self-help intervention designed to reduce problem drinking. The authors described the television is a media that could potentially enable low-threshold, low-cost dissemina- 
tion, and the television has a potential for health promotion interventions. The results showed that intervention appears effective in reducing problem drinking [16].

A study assessed the strategies used by individuals to access information about alcohol and other drugs available on web sites. Results suggest prudent use of text and information and clear and organized navigation options [17].

Therefore, information about psychoactive substances is released in different means, but its understanding is not evaluated. Access to quality information enables the individual to decide more clearly about their health-related behaviors, in this case, about behaviors related to substance abuse. Hence, it is important to evaluate the understanding of the information provided.

By analyzing each statement, it was noted that the question 10 of the pre-test and the 8 of the post-test answered correctly by all participants in the two study sites. The first addresses the changes that occur when the individual uses psychoactive substances. The second approaches the relationship between the dependent person and the substance. The dependent use is identified when signs and symptoms of tolerance are detected [18].

The changes that occur when the individual with disabilities uses psychoactive substances were described in study as physiological effects, the effects upon the person's mind and the financial implications, damage in the relationships with their families, partners and peers, often resulting in verbal and physical confrontations when drinking [19].

A study conducted with Portuguese students about alcohol use correlated the dependent pattern of use by men with secondary education and aged between 15 and 19 years old [4].

Study conducted with undergraduate students and nursing interns identified dependent pattern of use on alcohol in $0.4 \%$ of participants. Besides alcohol, it was found harmful use of tobacco, marijuana and sedatives [20].
In regarding the people with disabilities, study developed in Sweden with adolescents between 1516 years, with hearing loss and multiple disabilities identified that this group has a rate about eight times more of use illicit drug when compared "no disability" group and four times more when compared to "just hard hearing" group [21]

The highest proportion of correct answers occurred in the questions which described on the theme of discussion in schools, addiction, consequences and coping with drug use. The lowest proportion of correct answers is related with the question that describes the main reason for the use of drugs is the influence of friends.

Study conducted with Portuguese adolescents about the reasons for the use of illicit substances identified curiosity as the main reason for using drugs, which are obtained mainly through friends. The school was cited by $24.2 \%$ of respondents as the place of purchase of cannabis [22].

In Brazil, a survey with college students highlighted fun or pleasure; curiosity and relief of psychological stress as the main reasons for the use of psychoactive substances [23]. Another study identified the imposition of the group and lack of information about the effects as reasons for the use of psychoactive substances [24].

Self-medication, "psychological trauma", social distance from their community, loss, sadness, confusion are identified as the reasons for abuse substance by people with disabilities [19].

Other factors may be identified as crucial for the development of addiction, such as the influence of family and friends, and the relationship with the school and community [25].

It is emphasized that the questions of the tests were not matched on the theme and level of complexity. Thus, one can compare them in different ways. It is clear that information properly transmitted can assist in addressing substance abuse. 


\section{Conclusions}

This study achieved the proposed objective. It enabled to compare and to understand how information about psychoactive substances is understood by people with visual impairment. Such differences did not bring significant impacts related to information on the referred theme.

It was noted also that the study participants have information on the subject, but there are gaps in this information which it were demonstrated in regarding proportion de incorrect responses.

As study limitation, there is the conduction of the research in institutions that provide services to people with disabilities and associations, which may limit the generalization of the results. Further investigations must be carried out in more cities, especially in Portugal and also in other devices used by people with visual impairments, such as universities and libraries. In addition, it is recognized that the process of knowledge acquisition is a complex process because it involves several factors, which may not always be controlled, such as individual experience, individual ability of interpretation and memorization of content, among others.

The presented results contribute to the practice because they provide support for actions to prevent substance abuse, which use the information as a strategy. Furthermore, this study helps in reflecting on the evaluation of information provided. It was observed that the area with greatest knowledge among the study participants was dependence substance. So, this information can contribute to health professionals to elaborate yours education materials on substance abuse.

\section{Funding}

Study developed during a combined postdoctoral course in Porto, Portugal, with financial support from CAPES.

\section{References}

1. World Health Organization. Global status report on alcohol and health. Geneva: WHO Library Cataloguing-in-Publication; 2014.

2. II Levantamento Nacional de Álcool e Drogas (LENAD)-2012. Ronaldo Laranjeira (Supervisão) [et al.], São Paulo: Instituto Nacional de Ciência e Tecnologia para Políticas Públicas de Álcool e Outras Drogas (INPAD), UNIFESP. 2014

3. Serviço de Intervenção nos Comportamentos Aditivos e nas Dependências: Divisão de Estatística e Investigação e Divisão de Informação e Comunicação. Relatório Anual 2012 - A Situação do País em Matéria de Drogas e Toxicodependências. Editorial do Ministério da Educação e Ciência. 2013. Available from: http://www.sicad.pt/BK/Publicacoes/Lists/SICAD PUBLICACOES/Attachments/59/Relatorio Anual 2012.pdf

4. Santana SM, Negreiros J. Consumo de álcool e depressão em jovens portugueses. Revista Toxicodependências. 2008; 14(1): 17-24.

5. Sanchez ZVDM, Oliveira LG, Ribeiro LA, Nappo SA. The role of information as a preventive drug measure among youth at risk. Ciênc. Saúde Coletiva [Internet]. 2011; [cited 13 may 2014];16(Supl. 1):1257-1266. Disponível em <http:// www.scielo.br/scielo.php?script=sci arttext\&pid=S1413$81232011000700058 \& \operatorname{lng}=p t \& n r m=i s o>$.

6. Pagliuca LMF, Cezario KG, Mariano MR. Blind men and women' perceptions of the use of illegal drugs. Acta Paul Enferm. [Internet]. 2009 [cited 13 sept 2012]; 22(4): 404-11. Available from: <http://www.scielo.br/pdf/ape/v22n4/a09v22n4>

7. Brasil. A pessoa com deficiência e o Sistema Único de Saúde. 2. ed. Brasília: Editora do Ministério da Saúde; 2008.

8. Cezario KG, Pagliuca LMF. Assistive health technology for the blind people: a focus on drugs prevention. Esc. Anna Nery. 2007; 11(4):677-681.

9. Guimarães FJ, Pagliuca LMF. Assistive technology: an analysis of the concept. J Nurs UFPE on line. 2012; 6(11):2663-2671.

10. Oliveira LMB. Cartilha do Censo 2010: pessoas com deficiência. Brasília: SDH-PR/SNPD; 2012.

11. Salles OS, Castro RCBR. Validation of the informative material for patients and their families undergoing chemotherapeutical treatment. Rev. Esc. de Enferm USP [Internet] 2010 [Cited 07 june 2014];44 (1):182-9, mar. 2010. Available from: <http://www.scielo.br/scielo.php?pid=S008062342010000100026\&script=sci_arttext $>$.

12. PASQUALI, L. Instrumentação psicológica: fundamentos e práticas. Porto Alegre: Artmed; 2010.

13. Cavaco A, Santos AL. Evaluation of health literacy and the readability of information leaflets. Rev. Saúde Pública. 2012; 46(5):918-922 
14. Escola Nacional de Saúde Pública. Universidade de Lisboa. Questionário de Literacia em Saúde em Portugal: apresentação dos resultados preliminares. Available from: http://www. saudequeconta.org/index.php/site/literacia. Cited 08 dec. 2014.

15. Santos SMS, Oliveira ML. Knowledge about AIDS and Drugs among undergraduate students in a higher education institution in the state of Paraná. Rev. Latino-am de Enferm. [Internet] 2009 [cited 13 may 2014]; 7(4). Available from:<http://www.scielo.br/ pdf/rlae/v17n4/pt 14.pdf >.

16. Kramer J, Riper H, Lemmers L, Conijn B, Straten A V, Smit F. Television-supported self-help for problem drinkers: A randomized pragmatic trial. Addictive Behaviors. 2009; 34:451457

17. Kay-Lambkin FJ, White A, Baker AL, Kavanagh DJ, Klein B, Proudfoot J, et al.. Assessment of function and clinical utility of alcohol and other drug web sites: An observational, qualitative study. BMC Public Health [Internet] 2011 [cited 13 may 2014]; 11:277. Available from: http://www.biomedcentral.com/1471$\underline{2458 / 11 / 277}$

18. Diehl A, Cordeiro DC, Laranjeira R, col. Dependência química: prevenção, tratamento e políticas públicas. Porto Alegre: Artmed; 2011

19. Taggart L, McLaughlin D, Quinn B, McFarlane C. Listening to people with intellectual disabilities who misuse alcohol and drugs. Health Soc Care Community. 2007; 15(4):360-8.

20. Soares MH, Luís MAV, Corradi-Webster CM, Martins JT, Hirata AGP. Conceito psicológico de otimismo e uso de drogas entre estudantes de enfermagem. Acta Paul. Enferm [Internet] 2011 [cited 23 oct 2015]; 24(3):393-399. Available from: http:// www.scielo.br/scielo.php?script=sci arttext\&pid=S010321002011000300014\&lng=en\&tIng=pt.

21. Brunnberg E, Boström ML, Berglund M. Self-Rated Mental Health, School Adjustment, and Substance Use in Hard-ofHearing Adolescents. J Deaf Stud Deaf Educ. 2008; 13(3):32435.

22. Neto C, Fraga S, Ramos E. Illicit substances use by Portuguese adolescents. Rev Saúde Pública. 2012;46(5):808-15
23. Medeiros SB, Rediess SV, Hauck Filho N, Martins MIM, Mazoni CG. Prevalência do uso de drogas entre acadêmicos de uma universidade particular do sul do Brasil. Aletheia [a Internet]. 2012 [cited 24 sept 2014];(38-39):81-93. Available from: http:// pepsic. bvsalud.org/scielo.php?script=sci arttext\&pid=S141303942012000200007\&lng=pt.

24. Cirino DCS, Alberto MFP. Uso de drogas entre trabalhadores precoces na atividade de malabares. Psicologia em Estudo [Internet] 2009 [cited 23 oct 2015]; 14(3): 547-555. Available from http://www.scielo.br/scielo.php?script=sci_arttext\&pid=\$141373722009000300016\&lng=en\&tlng=pt.

25. Dietz G, Santos CG, Hildebrandt LM, Leite MT. As relações interpessoais e o consumo de drogas por adolescentes. SMAD. Revista eletrônica saúde mental álcool e drogas. [Internet] 2011 [cited 24 sept 2015];7(2):85-91. Available from: http:// pepsic.bvsalud.org/scielo.php?script=sci arttext\&pid=\$180669762011000200006\&lng=pt\&tlng=pt.
Publish in International Archives of Medicine

International Archives of Medicine is an open access journal publishing articles encompassing all aspects of medical science and clinical practice. IAM is considered a megajournal with independent sections on all areas of medicine. IAM is a really international journal with authors and board members from all around the world. The journal is widely indexed and classified Q2 in category Medicine. 